\title{
Effects of mechanical activation on the fluxing properties of Gua Musang Feldspar
}

\author{
R. Othman ${ }^{1}$, Z. Mustafa ${ }^{1 *}$ and L. Ting ${ }^{2}$ \\ ${ }^{1}$ Advanced Manufacturing Centre, Faculty of Manufacturing Engineering, \\ Universiti Teknikal Malaysia Melaka, 76100 Durian Tunggal, Melaka, Malaysia \\ *Email: zaleha@utem.edu.my \\ Phone: +6063316533; Fax: +6063316411 \\ ${ }^{2}$ School of Materials \& Mineral Resources Engineering, Engineering Campus, \\ Universiti Sains Malaysia, 14300 Nibong Tebal, Penang, Malaysia
}

\begin{abstract}
In this study, the relationship between milling duration and contamination, softening point, particle size and colour of Gua Musang Feldspar samples upon firing was determined. Feldspar is one of the components used in the manufacturing of clay-based ceramic products. The function of feldspar in the production of ceramics is to reduce the firing temperature, so that the energy upon firing can be saved in actual industrial production. The feldspar component is the first to melt in a typical clay-feldpar-silica triaxial porcelain compositions. The softening temperature of feldspar in the firing process is greatly affected by changes in the characteristics of the feldspar used, i.e., particle size, type and amount of alkali oxide content, etc. Other than size reduction, milling also invokes contamination due to the milling media. Contamination during milling at various milling duration using zirconia and stainless steel milling media was determined. Stainless steel was found to be unsuitable for use as the milling media because it affected the colour of the powder before and after firing. Even though contamination still took place when a zirconia milling media was used, zirconia was found to be a better choice because the contamination was much smaller, i.e., less than $1 \%$ at the longest milling duration of 20 hours. Hence, it would not affect the firing properties of the ceramic products and the original colour of the feldspar still remained the same as before milling. As milling proceeded into an ultrafine region, it became more and more difficult to obtain further reduction in size because a mill limit was reached. It was ascertained that as the milling duration increased, the softening point of the GMF showed a marked decrease in temperature from $925^{\circ} \mathrm{C}$ to $775^{\circ} \mathrm{C}$, a difference of $150 \mathrm{degC}$. Characterisation studies with commercial potash and soda feldspars confirmed that the Gua Musang Feldspar is a type of soda feldspar.
\end{abstract}

Keywords: Mechanical activation; milling media; feldspar; ceramic products.

\section{INTRODUCTION}

Powder processing is considered an important activity in the ceramic industry, and it includes ball milling of raw materials, blunging of ceramic powders in a liquid medium to form homogeneous slips or suspensions, spraying and pressing of powders, etc. Ceramics have been identified as one of the main fields, where improvements of processing and innovative and advanced products can be anticipated. Such products will have to be manufactured using the processing technology that is more sophisticated and 
better controlled [1]. Advances in ceramic processing and manufacturing technology will be inevitable for the commercialisation of new ceramic products. These improvements may eliminate the expensive steps, improve productivity and increase product reliability [2]. There are many challenges in the ceramics industry such as an increase in material costs, unavailability of raw materials, soaring energy costs and slumps in productivity and profits. The milling of coarse-grain material to produce fine powders is also of concern in many areas of ceramics. Milling operations involve a large amount of energy consumption and high capital equipment costs. These factors have received much attention in the field of mineral processing [3]. During mechanical milling or mechanical activation (MA), the contamination of powders is a major concern. The small size of the powder particles, availability of large surface area and formation of new surfaces during milling contribute to the contamination of the powder. Milling duration is the most important parameter. It should be realised that the level of contamination increases and some undesirable phases formed if the powder was milled for times longer than required. Therefore, it is desirable that the powder is milled just for the required duration to prevent excessive milling. In this work, zirconia and stainless steel were used as the milling media (milling balls and jars). When the milling duration is increased, the percentage of contamination of the powder by the milling media increases while the particle size decreases. The latter would affect the softening temperature of the feldspar [4, 5]. Ball milling is a process that consumes high amount and cost of energy. As ultrafine particles are obtained in milling; it becomes more and more difficult to obtain further reduction in size because a mill limit has been reached [6]. As the milling time increases, the energy required to continue the process further is also higher. A milling process is the breaking down of relatively coarse materials to the ultimate fineness. Ball milling has evolved from being a standard technique in mineral dressing and powder metallurgy, used primarily for particle size reduction, to its present status as an important method for preparation of either materials with enhanced physical and mechanical properties or new engineering materials [7]. The objectives of this project are to study the effect of different milling duration on the particle size distribution of GMF and to study the effect of different particle sizes in lowering the softening temperature of GMF.

\section{MATERIALS AND METHODS}

\section{Materials}

The main raw materials used in this project were Gua Musang Feldspar (GMF) samples obtained from a local ceramic manufacturing plant (Kim Hin Ceramics Sdn. Bhd.) in Senawang, Negeri Sembilan. In terms of characterisation, the GMF samples were compared with the commercial potash and soda feldspars. The GMF was sampled using the quartering method [8], before the apportioned sample was dried overnight at $100^{\circ} \mathrm{C}$ in a Memmert oven, whilst the commercial feldspars were pure and dry powders that needed no drying. All feldspars were characterised for chemical compositions using a RIX 3000 Rigaku, Japan, x-ray fluorescence (XRF) spectrometer and mineralogically analysed using a Bruker D8 Advance (Germany) x-ray diffraction (XRD) equipment.

\section{Milling Process}

A planetary mono mill, Pulverisette 6, was used in this work to investigate the effect of mechanical activation on the GMF samples. Only the GMF samples were milled because the potash and soda feldspars were processed commercial powders with homogeneous particle sizes. About 100g of each of the GMF sample were used for milling with the 
process parameters set as follows: zirconia milling media (balls and jar), milling speed of $400 \mathrm{rpm}$, ball-to-powder ratio of 1.5 to 1 , and milling duration of 5, 10, 15 and 20 hours. One GMF sample was also milled for 10 hours using a stainless steel milling media for comparison.

\section{Tests After Mechanical Activation}

After mechanical activation, the samples were examined by XRF and XRD. Particle size analysis was conducted on the milled powders. Contamination in the milled powders was also examined. Softening point of the milled powders was determined using a dilatometer on a $(4 \times 4 \times 20) \mathrm{mm}$ pressed specimens. Pressed pellets of $13 \mathrm{~mm}$ diameter and $4 \mathrm{~mm}$ thick, were heated at $10 \mathrm{deg} . \mathrm{C} / \mathrm{min}$ up to temperatures of $1100^{\circ} \mathrm{C}, 1200^{\circ} \mathrm{C}, 1250^{\circ} \mathrm{C}$ and $1300^{\circ} \mathrm{C}$ for 1 hour soaking period. Henceforth, changes in colour were observed.

\section{RESULTS AND DISCUSSION}

\section{Characterisation of Raw Materials}

The chemical composition of the three feldspars is tabulated in Table 1. It is obvious that the $\mathrm{K}_{2} \mathrm{O}$ content in the potash feldspar is the highest, whilst the $\mathrm{Na}_{2} \mathrm{O}$ content is the highest in the soda feldspar. The $\mathrm{Na}_{2} \mathrm{O}$ content in the GMF is the second highest after that of soda feldspar, whilst its $\mathrm{K}_{2} \mathrm{O}$ content is much closer to that of the soda feldspar and very much less than that of the potash feldspar.

Table 1. Chemical composition of GMF, potash feldspar and soda feldspar.

\begin{tabular}{cccc}
\hline & Gua Musang Feldspar & Potash Feldspar & Soda Feldspar \\
\hline $\mathrm{Na}_{2} \mathrm{O}$ & 3.60 & 2.10 & 5.50 \\
$\mathrm{MgO}$ & 0.31 & 0.03 & 0.06 \\
$\mathrm{Al}_{2} \mathrm{O}_{3}$ & 22.00 & 18.00 & 20.00 \\
$\mathrm{SiO}_{2}$ & 68.00 & 67.00 & 69.00 \\
$\mathrm{SO}_{3}$ & 0.01 & - & 0.01 \\
$\mathrm{~K} 2 \mathrm{O}$ & 3.00 & 11.00 & 2.60 \\
$\mathrm{CaO}$ & 0.15 & 0.26 & 1.70 \\
$\mathrm{TiO}_{2}$ & 0.05 & - & 0.20 \\
$\mathrm{MnO}_{2}$ & 0.09 & - & - \\
$\mathrm{Fe}_{2} \mathrm{O}_{3}$ & 0.68 & 0.14 & 0.15 \\
$\mathrm{Rb}_{2} \mathrm{O}$ & 0.05 & 0.09 & 0.02 \\
$\mathrm{SrO}_{\mathrm{ZrO}}$ & 0.02 & - & 0.04 \\
$\mathrm{P}_{2} \mathrm{O}$ & 0.01 & - & 0.02 \\
$\mathrm{LOI}$ & - & - & 0.35 \\
\hline
\end{tabular}

Correspondingly, GMF can be said as a soda feldspar rather than a potash feldspar, the nature of which can be further ascertained by a mineralogical analysis as given in the $\mathrm{x}$-ray diffraction pattern in Figure 1 [9]. 


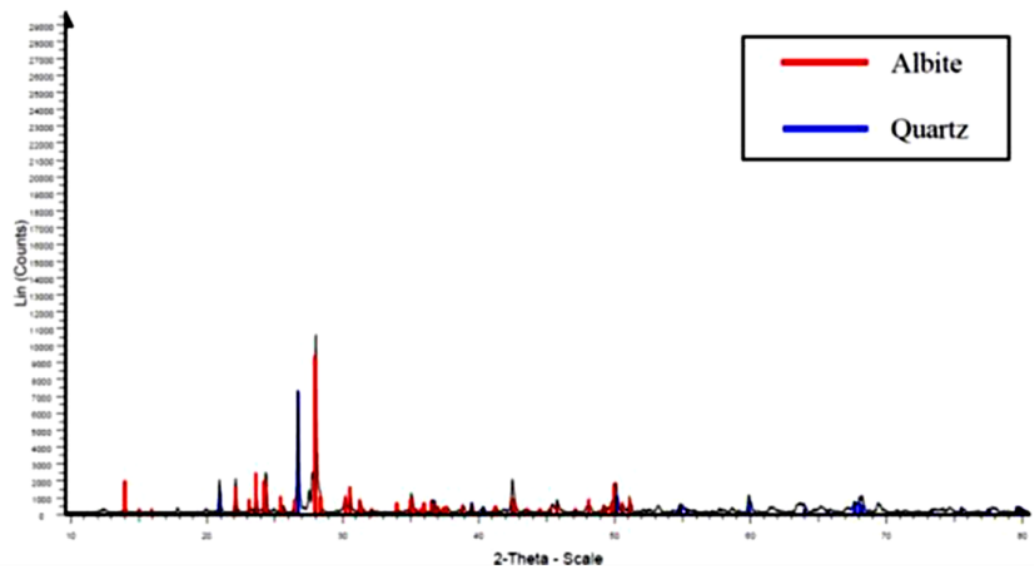

Figure 1. Diffractogram of GMF sample (Quartz is silica mineral, $\mathrm{SiO}_{2}$; Albite is a sodium feldspar mineral, $\mathrm{Na}_{2} \mathrm{O} \cdot \mathrm{Al}_{2} \mathrm{O}_{3} \cdot 6 \mathrm{SiO}_{2}$ ).

\section{XRF after Various Milling Duration}

Full XRF analyses were carried out on the GMF samples that were milled for four different milling duration using zirconia milling media. An additional analysis was also done on a GMF sample that was milled for 10 hours using a stainless steel milling media for comparison. Only an abridged version of the analyses is shown in Table 2, which principally highlights the $\mathrm{ZrO}_{2}$ and $\mathrm{Fe}_{2} \mathrm{O}_{3}$ contents. The amount of contamination using zirconia milling media is very small after 5-20 hours of milling. On the other hand, contamination when using stainless steel media is quite significant even after only 10 hours of milling.

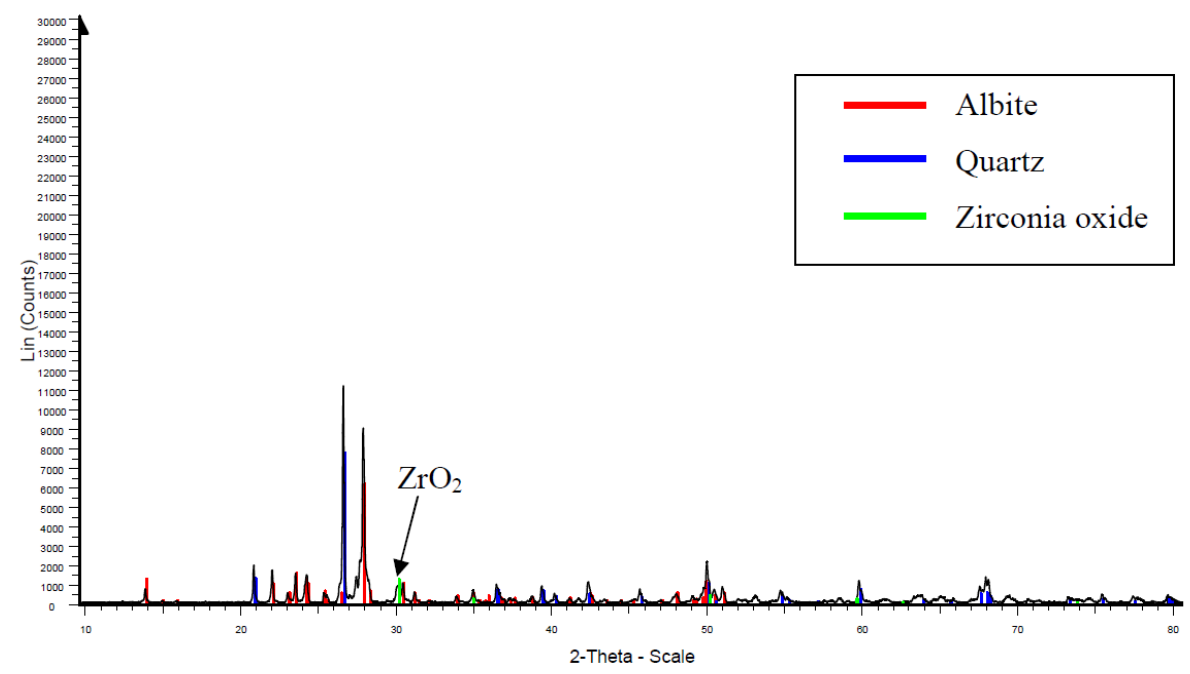

Figure 2. Detection Of A Zirconia Contaminant Phase Upon Milling Using A Zirconia Milling Media For 5 Hours.

\section{XRD after various milling duration}

XRD patterns after being milled for duration of 5, 10, 15 and 20 hours show that all the zirconia-milled samples exhibit the presence of a zirconia phase as shown in Figure 2. Likewise, the sample milled using the stainless steel milling media exhibit the presence of an increased $\mathrm{Fe}_{2} \mathrm{O}_{3}$ phase (this diffractogram is not shown in this paper). 
Table 2. $\mathrm{ZrO}_{2}$ contamination (weight.\%) after various milling duration using zirconia milling media (a sample milled using stainless steel media is included for comparison).

\begin{tabular}{ccccccc}
\hline & Original & SS10 hrs, $\%$ & $5 \mathrm{hrs}, \%$ & $10 \mathrm{hrs}, \%$ & $15 \mathrm{hrs}, \%$ & $20 \mathrm{hrs}, \%$ \\
\hline $\mathrm{ZrO}_{2}$ & 0.014 & 0.038 & 0.066 & 0.032 & 0.310 & - \\
$\mathrm{Fe}_{2} \mathrm{O}_{3}$ & 0.680 & 0.650 & 0.650 & 0.640 & 0.650 & 1.200 \\
\hline
\end{tabular}

\section{Particle Size After Milling}

The particle size distribution of the powders, which were milled for different duration, is shown in Figure 3. Upon milling, the original GMF powder shows a marked decrease in size (as depicted by the blue curve). As the milling duration is increased, the size distribution becomes smaller, but at present the reduction has become much more sluggish.

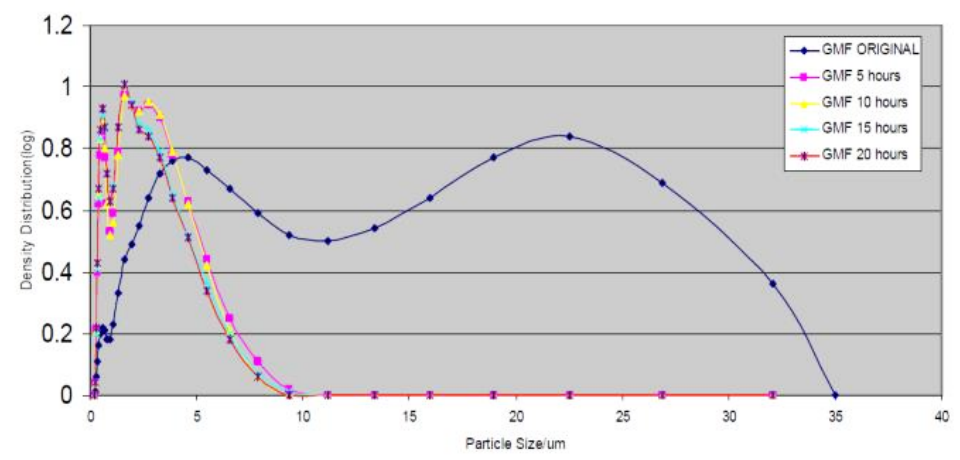

Figure 3. Particle Size Distribution of GMF After Being Milled For Various Duration.

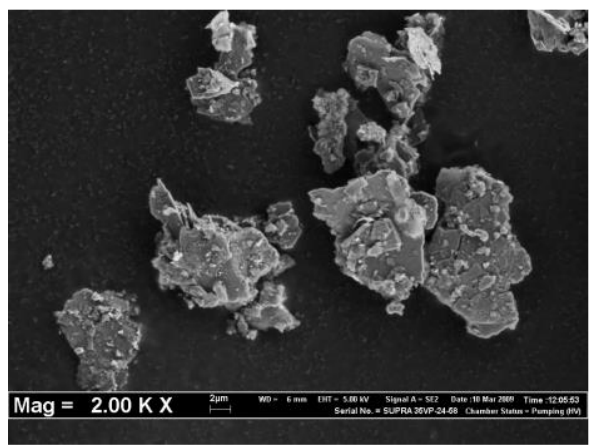

(a)

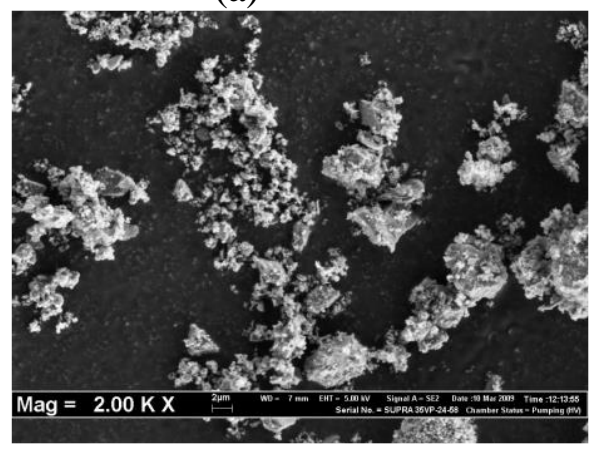

(c)

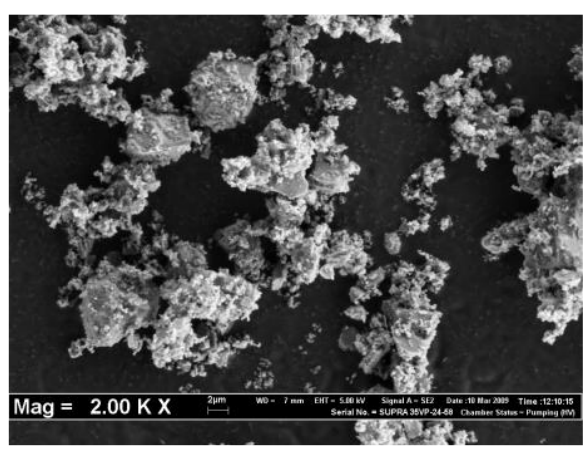

(b)

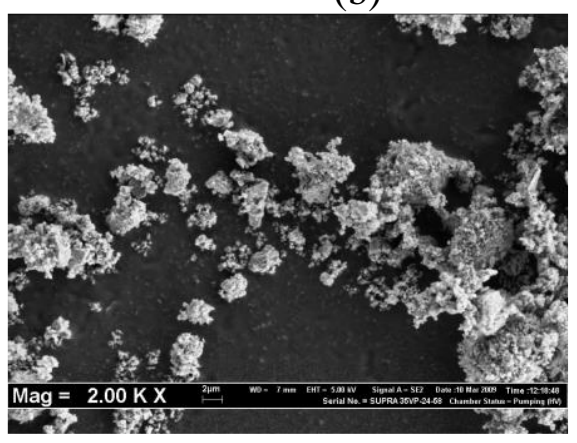

(d)

Figure 4. Scanning Electron Micrographs of GMF Powders After Being Milled for (a) 5, , b) 10, (c) 15 and (d) 20 hours. 
The actual reduction in size can be viewed from the scanning electron micographs of the powders after being milled for 5, 10, 15 and 20 hours (Figure 4).

\section{Softening Points After Various Milling Duration}

Table 3 shows the softening points of specimens fabricated from powders that were unmilled and milled using a zirconia milling media for 5, 10, 15 and 20 hours. A GMF sample that was milled for 10 hours using stainless steel media is also included in Table 3 for comparison.

Table 3. Softening temperatures of GMF samples milled for different milling duration using zirconia media (one using a stainless steel media is included for comparison).

\begin{tabular}{lc}
\hline \multicolumn{1}{c}{ Samples } & Softening Temperature $\left({ }^{\circ} \mathrm{C}\right)$ \\
\hline GMF (original) & 925 \\
GMF 5 hours & 825 \\
GMF 10 hours & 825 \\
GMF 15 hours & 825 \\
GMF 20 hours & 775 \\
GMF 10 hours-Stainless steel & 825 \\
\hline
\end{tabular}

There is a marked decrease in softening point for sample that was milled for 5 hours $\left(825^{\circ} \mathrm{C}\right)$ compared to the original unmilled GMF sample $\left(925^{\circ} \mathrm{C}\right)$. Subsequent increment of 5 hours of milling (10 and 15 hours) does not exhibit any signicant reduction in softening point up to the duration of 20 hours of milling, where the softening point further decreases to $775^{\circ} \mathrm{C}$. The decrease in softening point is attributed to the energy imparted to the powder particles due to mechanical activation process [10, 11]. The stability of the softening point between 5 to 15 hours of milling allows milling process variability in the actual industrial production line. In terms of temperature reduction, the stainless steel media produces a comparable result as the zirconia media within a comparable duration range.

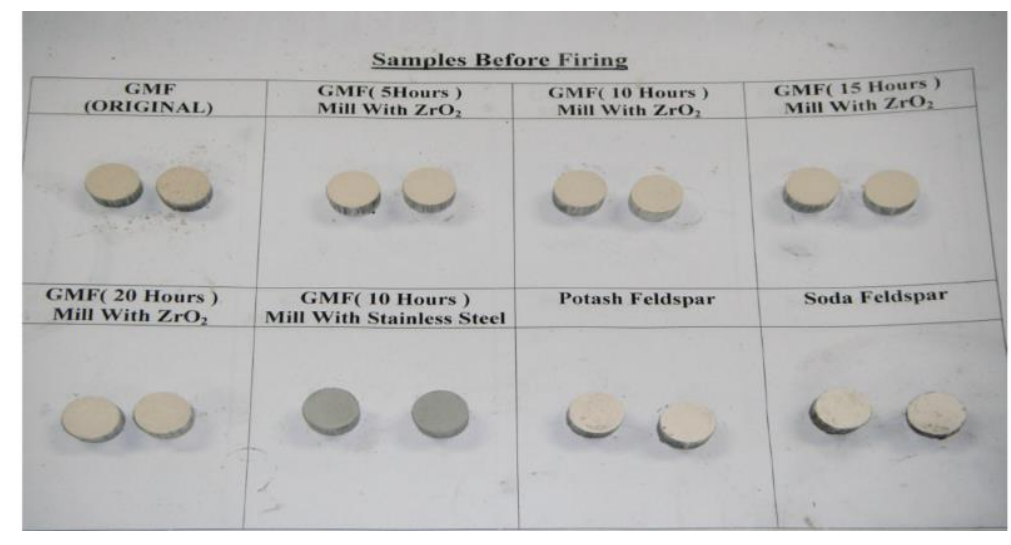

Figure 5. Feldspar Specimens Before Firing.

\section{Colour Changes before and after Firing}

Nonetheless, the effect of using the stainless steel media is more significant when the colour of the resultant powder, before and after firing, is taken into account. The colour 
of the fired GMA, milled using the zirconia milling media, is within acceptable limits when compared to the commercial feldspars, with the obvious advantage that it can be procured at a much lower price (Figure 5 and 6).

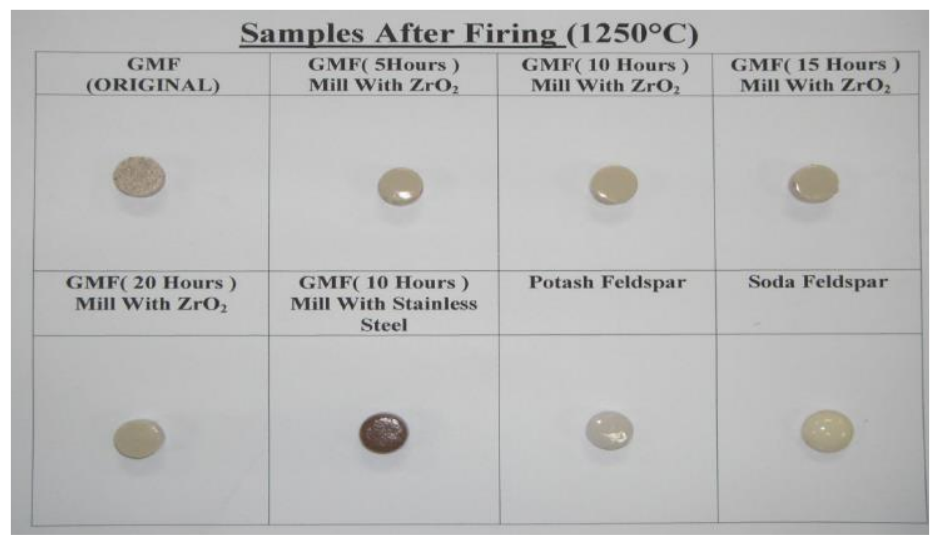

Figure 6. Feldspar Specimens After Firing at $1250{ }^{\circ} \mathrm{C}$.

\section{CONCLUSIONS}

This work has succeeded in establishing that the GMF is a soda feldspar which fires up to a light grey colour upon firing. This is comparable to the firing colour of commercial feldspars that are normally imported from overseas. Contamination using zirconia milling media is very minimal up to 20 hours of milling. Milling using the zirconia media has succeeded in lowering the softening temperature of GMF by $100{ }^{\circ} \mathrm{C}$ when milled up 5 to 15 hours of milling, and a further $50^{\circ} \mathrm{C}$ when the milling duration is continued up to 20 hours. Hence, GMF is a suitable feldspar which can be resourced within Malaysia and has shown gradual acceptance from the fraternity of the Malaysian ceramic industries.

\section{ACKNOWLEDGEMENTS}

The authors would like to acknowledge the support from Universiti Teknikal Malaysia Melaka and Universiti Sains Malaysia.

\section{REFERENCES}

[1] Berto AM. Ceramic tiles: Above and beyond traditional applications. Journal of the European Ceramic Society. 2007;27:1607-13.

[2] Handbook of ceramic grinding and polishing: properties, processes, technology, tools and typology. Park Ridge, NJ: Noyes Publications; 2000.

[3] Ceramic processing before firing. New York: Wiley; 1978.

[4] Das SK, Dana K. Differences in densification behaviour of K- and Na-feldsparcontaining porcelain bodies. Thermochimica Acta. 2003;406:199-206.

[5] Martín-Márquez J, Rincón JM, Romero M. Effect of firing temperature on sintering of porcelain stoneware tiles. Ceramics International. 2008;34:1867-73.

[6] Broseghini M, Gelisio L, D’Incau M, Azanza Ricardo CL, Pugno NM, Scardi P. Modeling of the planetary ball-milling process: The case study of ceramic powders. Journal of the European Ceramic Society. 2016;36:2205-12. 
[7] Carty WM, Senapati U. Raw materials, processing, phase evolution, and mechanical behavior. Journal of the American Ceramic Society. 1998;81:3-20.

[8] Jones MP. Applied mineralogy: a quantitative approach. London: Graham \& Trotman; 1987.

[9] Othman R, Mohamad M. Firing behaviour of ceramic whiteware bodies incorporated with local feldspathic sources. Jurnal Teknologi. 2016;78:19-23.

[10] Suryanarayana C, Ivanov E, Boldyrev VV. The science and technology of mechanical alloying. Materials Science and Engineering: A. 2001;304-306:1518.

[11] Suryanarayana C. Mechanical alloying and milling. Progress in Materials Science. 2001;46:1-184. 